\title{
PENATALAKSANAAN FISIOTERAPI UNTUK GANGGUAN FUNGSIONAL LUMBAL PADA KASUS HERNIA NUKLEUS PULPOSUS DENGAN TEKNIK PNF, TENS DAN MCKENZIE EXERCISE DI RSUD ULIN BANJARMASIN TAHUN 2019
}

\author{
(Management of Physiotherapy for Lumbar Functional Disorders \\ due to Hernia Nucleus Pulposus with PNF Technique, TENS and \\ McKenzie Exercise at RSUD Ulin Banjarmasin 2019)
}

\author{
Winda Yasinta Dwi ${ }^{1}$, Mu'jizatillah $^{1}$, Enny Fauziah ${ }^{1}$ \\ Program Studi DIII Fisioterapi Politeknik Unggulan Kalimantan ${ }^{1}$
}

Email: mujizatillah@polanka.ac.id

\begin{abstract}
Hernia Nucleus Pulposus (HNP) is a protrusion of intervertebral disc that occurs due to an injury or a wrong mechanical load for a long time. The aim of the study was to find out physiotherapy management of HNP and whether there was an increase lumbar functional ability after given physiotherapy intervention with Transcutaneous Electrical Nerve (TENS), Proprioceptive Neuromuscular Fasilitation (PNF), and McKenzie Exercise. This study used a case study method of one HNP patient. Physiotherapy treatment were done 12 times in 6 weeks. Measuring tool to determine the disorders of lumbar functional activity is the Oswestry Disability Index (ODI). The result of the study obtained after evaluation is there an increase in lumbar functional activity after treatment with TENS, PNF and McKenzie Exercise.
\end{abstract}

Keywords : HNP, TENS, PNF, McKenzie Exercise

\begin{abstract}
ABSTRAK
Hernia Nucleus Pulposus (HNP) adalah kondisi dimana terjadi protrusi pada diskus intervertebralis karena cedera atau beban mekanik yang salah dalam waktu yang lama. Tujuan penelitian ini adalah untuk mengetahui penatalaksanaan fisioterapi pada kondisi HNP dan apakah ada peningkatan fungsional lumbal setelah diberikan intervensi fisioterapi berupa Transcutaneus Electrical Nerve Stimulation (TENS), Proprioceptive Neuromuscular Facilitation (PNF), dan McKenzie Exercise. Penelitian ini menggunakan metode case study dengan menggunakan satu sampel pasien HNP. Treatment dilakukan sebanyak 12 kali dalam kurun waktu 6 minggu. Alat ukur untuk mengetahui gangguan aktivitas fungsional lumbal yaitu Oswestry Disability Index (ODI). Hasil penelitian yang didapatkan setelah dilakukan evaluasi yaitu adanya peningkatan aktivitas fungsional lumbal setelah diberikan intervensi TENS, PNF dan Mckenzie Exercise.
\end{abstract}

Kata kunci : HNP, TENS, PNF, McKenzie Exercise 


\section{PENDAHULUAN}

Lumbal merupakan daerah paling besar yang menerima beban saat tubuh bergerak dan saat menumpu berat badan apabila dipandang dari segi anatomis dan fungsional. Hal ini membuat tulang belakang sangat peka terhadap terjadinya cidera atau kerusakan sehingga sering mengalami gangguan dan mengurangi kualitas hidup individu (Tanderi et al., 2017).

Masalah Nyeri Punggung Bawah (NPB) menjadi penting untuk diteliti karena merupakan salah satu keluhan yang sering ditemui di semua lapisan masyarakat dan menjadi salah satu alasan paling umum yang membuat orang tidak dapat bekerja atau melakukan kegiatannya dengan baik. Diperkirakan, $80 \%$ penduduk selama hidup pernah merasakan NPB (Roselina et al., 2014) dan sekitar 40\% nyeri punggung bawah disebabkan oleh hernia nukleus pulposus (Fatmasari, 2016).

Hernia Nucleus Pulposus (HNP) adalah kondisi dimana terjadi protrusi pada diskus intervertebralis karena cedera atau beban mekanik yang salah dalam waktu yang lama. Selain itu faktor utama yang menyebabkan HNP adalah usia karena elastisitas dari annulus fibrosus menurun sehingga menyebabkan robeknya annulus fibrosus (Cahyati, 2015).

Prevalensi kejadian HNP adalah sekitar 1-3\% di negara Finlandia dan Italia. Angka kejadian HNP tertinggi adalah 5 dari 20 kasus nyeri punggung bawah per 100 orang dewasa setiap tahun, dan paling sering terjadi pada orang berusia 30 hingga 50 -an, dengan rasio pria dan wanita adalah 2:1 (Jordan et al., 2009). Adapun prevalensi pasien HNP di RSUD ULIN Banjarmasin mulai Januari-Desember 2018 sebanyak 140 pasien (Data primer, 2018).

HNP sendiri dapat menyebabkan berbagai keluhan seperti nyeri dan kesemutan pada pinggang bawah hingga tungkai, spasme, keterbatasan lingkup gerak sendi serta adanya penurunan kekuatan otot yang dapat mengganggu aktivitas fungsional penderita (Surya, 2015). Banyaknya jumlah penderita dan permasalahan yang muncul menyebabkan berbagai pengobatan terus dikembangkan termasuk pengobatan dari segi fisioterapi. Menurut Sudaryanto \& Islam (2018), dalam penelitiannya mengatakan bahwa intervensi TENS, PNF, dan McKenzie Exercise dapat memberikan pengaruh yang signifikan terhadap perubahan fungsional lumbal pada penderita HNP lumbal.

TENS (Transcutaneus Electrical Nerve Stimulation) merupakan salah satu modalitas terapi elektro berupa impuls listrik yang berfungsi sebagai pemblok impuls nyeri yang dirasakan oleh pasien sehingga akan mengakibatkan nyeri berkurang (Pranata et al., 2016). Menurut Jhonson (2009), pemberian intervensi TENS dengan frekuensi rendah mampu merangsang tubuh mengeluarkan endorphin. Endorphin yang keluar akan meningkatkan relaksasi kemudian diikuti oleh penurunan nyeri.

PNF (Proprioceptif Neuromuscular Fasilitation) adalah fasilitasi pada sistem neuromuskular dengan cara merangsang proprioseptif. PNF berdasarkan pada konsep bahwa kehidupan ini adalah reaksi atas sederetan rangsangan-rangsangan yang diterimanya (Alim, 2010). Tujuan PNF adalah memperoleh kuantitas maksimal dari aktivitas yang dapat dicapai seseorang dalam setiap usaha. Selain itu seseorang akan memperoleh pengulangan aktivitas yang maksimal untuk memudahkan timbulnya respon (Budiono, 2016). 
McKenzie Exercise merupakan terapi latihan yang mengutamakan gerakan ekstensi. Tujuan dari McKenzie exercise adalah mencapai dan mempertahankan postur normal lordosis vertebrae, mengurangi penekanan posterior pada diskus intervertebralis dan ligament vertebrae. McKenzie exercise adalah metode perbaikan tulang belakang dengan gerak ekstensi. Pada gerakan ekstensi, nucleus pulposus akan terdorong ke anterior akibat dari meningkatnya tekanan di posterior. Sehingga jika latihan ini dilakukan dengan rutin dan ritmis akan mereposisi posisi nucleus pulposus dalam annulus fibrosus yang mengalami herniasi (Nugroho et al., 2018). Banyaknya penelitian tentang modalitas terapi yang baik untuk pasien HNP, membuat peneliti tertarik untuk melakukan penatalaksanaan fisioterapi dengan pemberian TENS, PNF dan McKenzie exercise pada pasien dengan kasus HNP untuk mengatasi fungsional lumbal.

\section{METODE PENELITIAN}

Jenis penelitian ini merupakan penelitian studi kasus (case study). Penelitian ini dilakukan di Poli Fisioterapi RSUD ULIN Banjarmasin. Adapun waktu penelitian dimulai bulan 03 Mei-15 Juni 2019.

Program fisioterapi dilaksanakan selama 12 kali pertemuan di ruang fisioterapi RSUD Ulin Banjarmasin dan di rumah pasien. Modalitas yang digunakan adalah TENS, PNF dan McKenzie exercise. Adapun TENS dioperasikan oleh fisioterapi dengan durasi 10 menit. Sedangkan PNF dilakukan 10 kali repitisi dengan frekuensi 12 kali pertemuan. dan McKenzie exercise dilakukan 2-3 menit diulangi 10 kali dengan frekuensi 12 kali pertemuan. Data yang diambil dari gangguan fungsional lumbal pada kondisi HNP adalah menggunakan Oswestry Disability Index (ODI).

Setelah diberikan intervensi fisioterapi, data yang diperoleh dengan ODI akan dilihat perkembangannya. Lalu data dianalisis melalui evaluasi selama dua belas kali dalam satu setengah bulan penelitian. Dari data tersebut dapat dilihat pengaruh pemberian modalitas fisioterapi tersebut pada kasus HNP dengan gangguan fungsional lumbal apakah mengalami peningkatan, menetap atau bahkan menurun.

\section{HASIL DAN PEMBAHASAN}

Berdasarkan hasil pemeriksaan fisioterapi diperoleh diagnosa fisioterapi berupa gangguan aktivitas fungsional lumbal akibat HNP grade 2 sejak 2 tahun yang lalu dengan problematik fisioterapi berupa nyeri punggung bawah saat diam dan juga saat beraktivitas, adanya spasme pada m.quadratus lumborum, m.erector spine dan adanya kelemahan pada otot-otot fleksor hip dan otot ekstensor hip serta otot fleksor lumbal yang pada akhirnya mengganggu aktifitas fungsional pasien.

Dari problematik yang didapatkan tersebut, pasien selanjutnya diberikan penatalaksanaan fisioterapi berupa TENS, PNF, dan McKenzie Exercise selama 12 kali pertemuan, dimulai dari tanggal 03 Mei-15 Juni 2019. Aktivitas fungsional pasien diukur dan dievaluasi menggunakan parameter berupa kuisioner Oswestry Disability Index (ODI) yang menilai 10 kriteria yaitu intensitas nyeri, perawatan diri, mengangkat benda, berjalan, duduk, berdiri, tidur, kehidupan sosial, bepergian, dan pekerjaan. Hasilnya digambarkan dalam gambar grafik berikut. 
Volume 2 No. 1 (April, 2020)

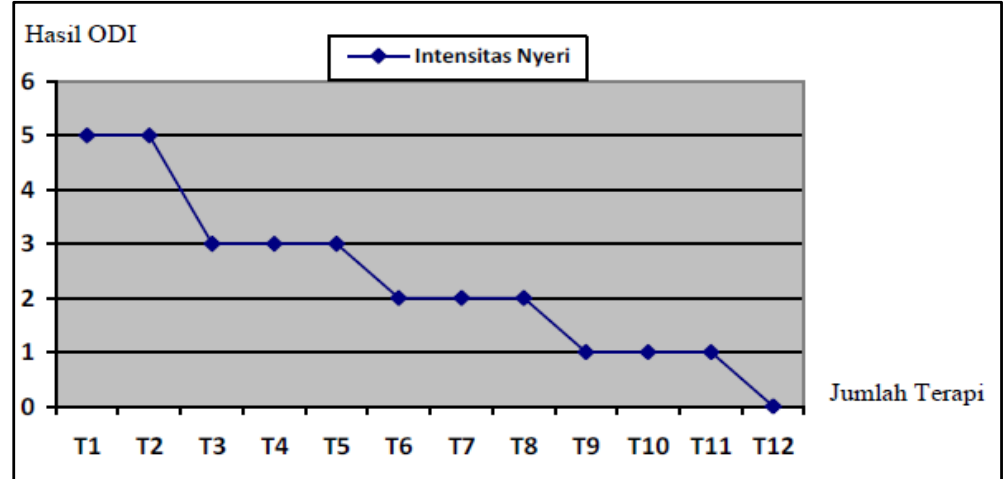

Gambar 1. Hasil pengukuran intensitas nyeri

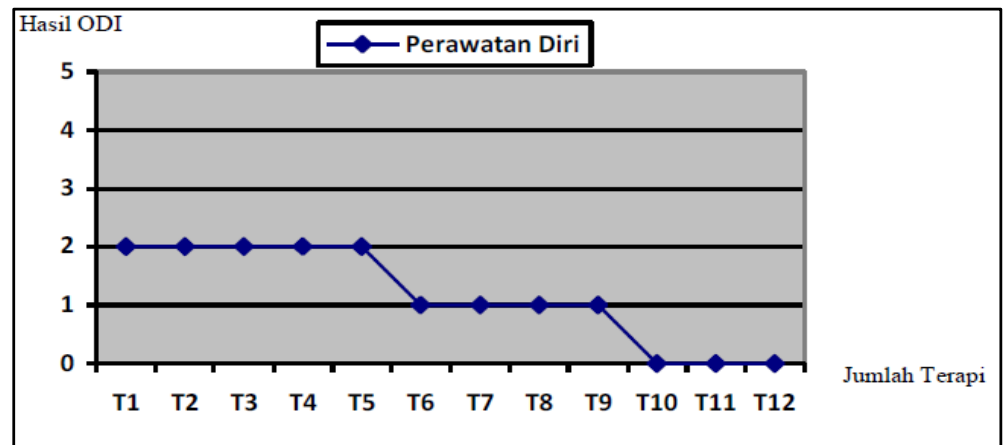

Gambar 2. Hasil pengukuran perawatan diri

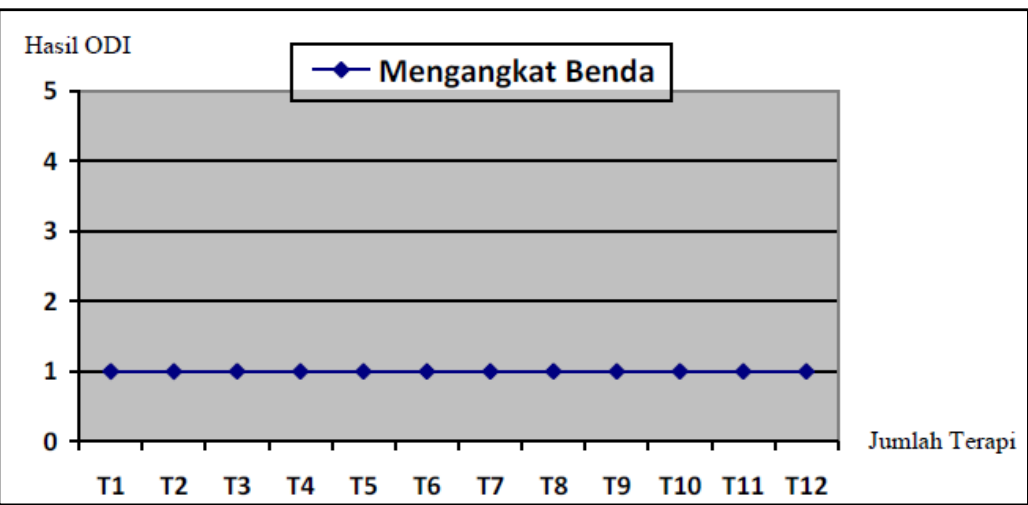

Gambar 3. Hasil pengukuran mengangkat benda

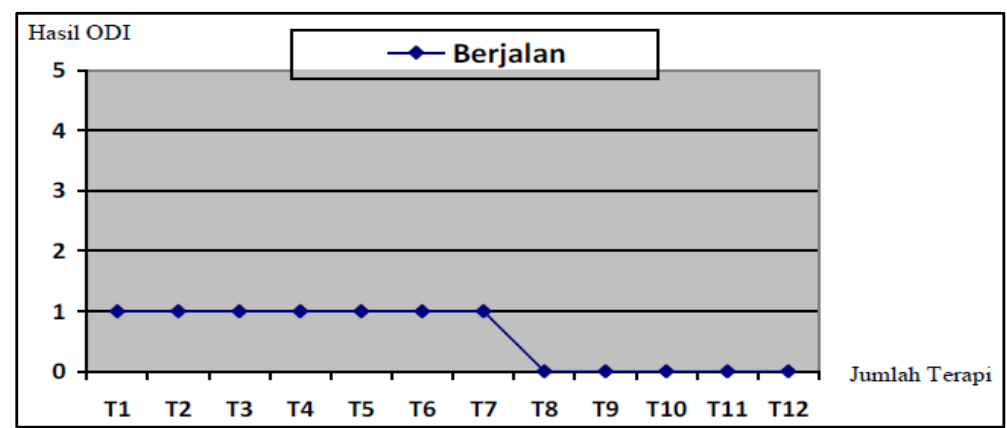

Gambar 4. Hasil pengukuran berjalan 


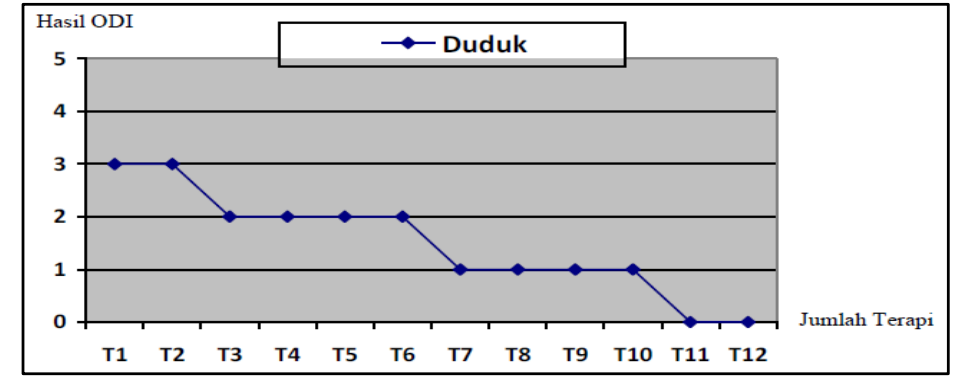

Gambar 5. Hasil pengukuran duduk

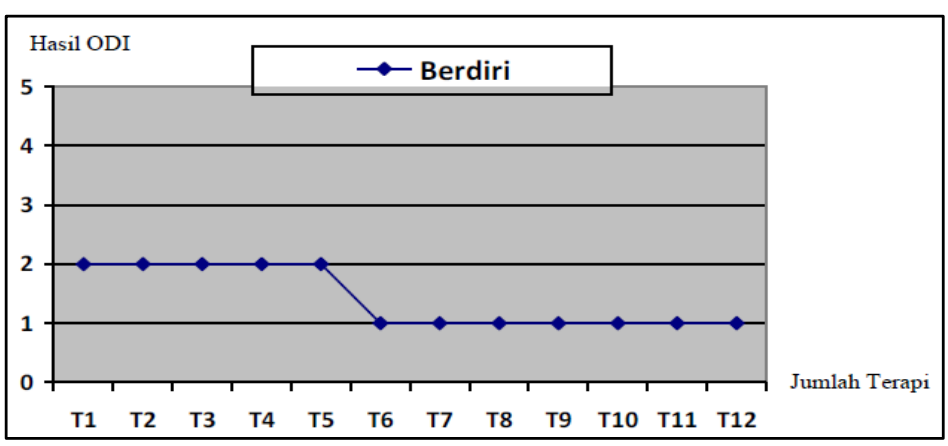

Gambar 6. Hasil pengukuran berdiri

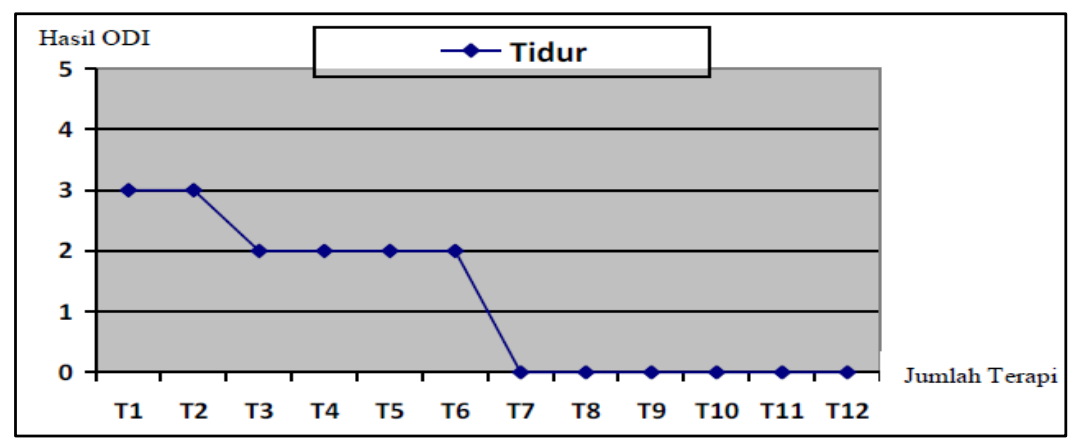

Gambar 7. Hasil pengukuran tidur

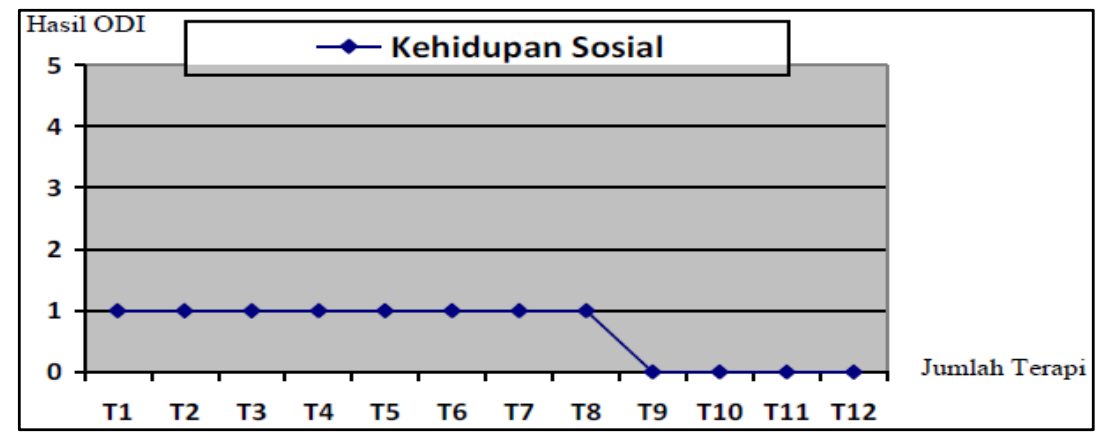

Gambar 8. Hasil pengukuran kehidupan sosial 


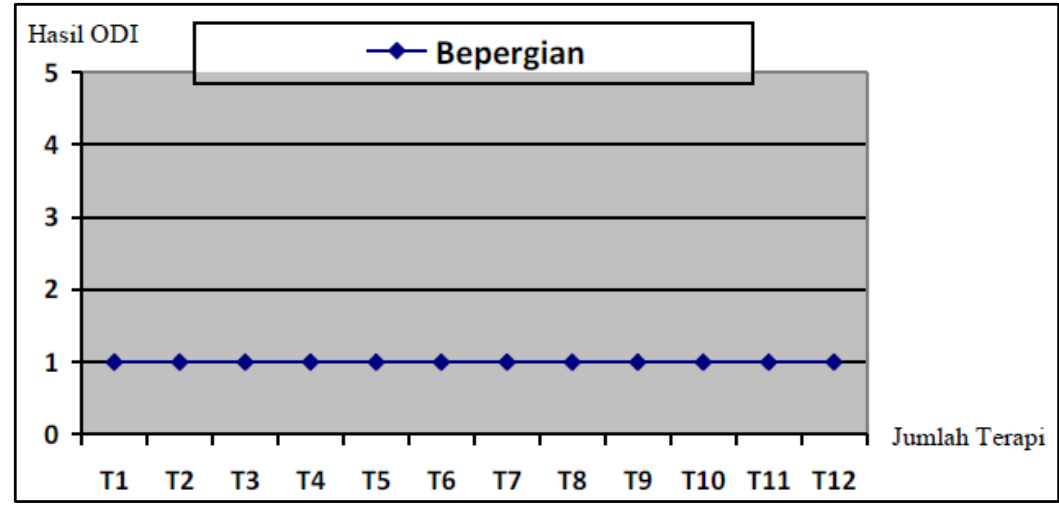

Gambar 9. Hasil pengukuran bepergian

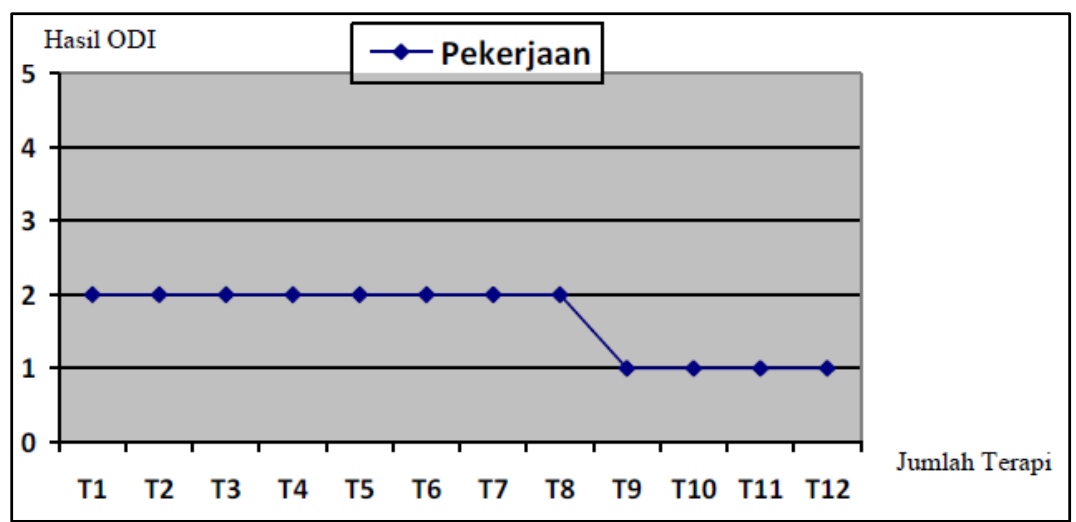

Gambar 10. Hasil pengukuran pekerjaan

Total skor ODI sebelum terapi adalah 21 dengan interpretasi disabilitas sedang, setelah terapi terjadi penurunan menjadi nilai 4 dengan interpretasi disabilitas ringan sehingga dapat dikatakan kondisi pasien jauh lebih baik dari sebelum dilakukannya penatalaksanaan fisioterapi. Dengan begitu modalitas fisioterapi berupa TENS, PNF, dan McKenzie exercise yang digunakan dalam penatalaksanaan fisioterapi kondisi HNP sangatlah berpengaruh pada peningkatan aktivitas fungsional lumbal yang dialami pasien.

TENS dapat mengurangi nyeri karena dapat menghambat reseptor nyeri (nosiseptor) sehingga mencegah impuls nyeri dihantarkan ke tingkat yang lebih tinggi di susunan saraf pusat. Dengan pemberian TENS maka serabut saraf berdiameter besar akan diaktivasi dan dapat mengaktivasi sel-sel interneuron di substansia gelatinosa sehingga susunan saraf berdiameter kecil terhalang menyampaikan rangsangan nyeri ke pusat saraf dan menutup "spinal gate". Dengan menutupnya "spinal gate" maka informasi nyeri terputus (Septiana, 2015).

TENS konvensional mampu mengaktivasi reseptor opioid- $\sigma$ secara lebih spesifik daripada resepor opioid-hu. Aktivitas ini terjadi di dalam medula spinalis dan medula ventral rostral dengan amplitudo yang diatur pada level sensori. TENS konvensional juga terbukti mampu meningkatkan pelepasan dinorfin yang mengaktifkan reseptor opioid-k terhadap respon anelgesia. TENS model konvensional merupakan pendekatan yang mengaktivasi serabut saraf tepi berdiameter besar untuk memodulasi saraf nyeri melalui mekanisme gerbang neurokimia supraspinal dan segmental. TENS pada intensitas level sensori juga mengurangi jumlah pelepasan zat $\mathrm{P}$ di dalam kornu dorsal dalam 
menyebabkan hipereksitabilitas sistem saraf pusat atau sensitisasi sentral. Penurunan pelepasan transmiter eksitatori di kornu dorsal oleh TENS akan mengurangi kemungkinan sensasi sentral berkembang (Hayes \& Hall, 2016). Dengan adanya perbaikan pada rasa nyeri maka dapat memberikan efek peningkatan kemampuan fungsional pasien yang sebelumnya mengalami penurunan.

Kemudian bukti klinis lain menunjukkan bahwa gerakan PNF memberikan kemudahan terhadap gerakan melalui impuls-impuls proprioseptik. Prinsip umumnya adalah dengan pemberian stimulasi tertentu untuk membangkitkan kembali mekanisme yang latent dan cadangan-cadangannya maka akan dicapai suatu gerak fungsional yang normal dan terkoordinasi (Aulia, 2015). Metode PNF dipilih karena terjadi penguatan dan gerak fungsional yang terjadi secara bersamaan, berbeda jika hanya dengan latihan konvensional yaitu penguatan dan gerak fungsional tidak terjadi secara bersamaan. Pemilihan metode PNF bertujuan untuk meningkatkan kekuatan otot, ROM, koordinasi, seperti halnya rehabilitasi selektif dari pembelajaran gerak dan penguatan/memperkuat melalui pengulangan (Llake, 2014).

Selain itu teknik PNF dapat menurunkan ketegangan otot quadratus lumborum dan piriformis. Penurunan ketegangan otot piriformis dapat menurunkan iritasi pada cabang saraf ischiadicus, sehingga nyeri ischialgia secara progresif dapat menurun. PNF merupakan salah satu metode yang efektif digunakan untuk meregangkan otot secara maksimal karena adanya stretching secara pasif dari otot yang mengalami ketegangan tersebut (Budiono, 2016). Menurut Hendrik (2018), dengan adanya peningkatan kekuatan otot, fleksibilitas dan penurunan ketegangan otot maka dapat memberikan dampak peningkatan kemampuan fungsional pasien.

Adapun McKenzie exercise merupakan suatu teknik latihan dengan menggunakan gerakan badan terutama ke arah ekstensi dan dapat meningkatkan aktifitas fungsional (Jumiati, 2015). Pada posisi ekstensi yang dipertahankan selama beberapa detik akan diperoleh perengangan pada jaringan lunak bagian anterior yaitu ligament anterior sehingga akan mengembalikan posisi pada posisi ekstensi/lordosis. Hal ini merupakan suatu counter position yang menimbulkan dorongan diskus ke anterior. Selanjutnya terjadi penekanan diskus ke sisi posterior, sehingga akan didapat gaya tangesial yang mendorong nucleus ke ventral. Akibat adanya gerak dinamis ekstensi yang dilakukan berulang dapat meningkatkan cairan diskus dan korpus yang kemudian akan menurunkan viskositas nucleus pulposus dan dapat mengurangi iritasi terhadap jaringan sekitarnya. Kondisi seperti ini membuat nyeri akan menurun dan aktivitas fungsional meningkat (Saputri, 2016). Hal ini sejalan dengan penelitian yang dilakukan oleh (Yuniar et al., 2013) yang menunjukkan bahwa McKenzie exercise efektif untuk menurunkan nyeri sehingga dapat menurunkan skor ODI pada kasus HNP.

\section{KESIMPULAN}

Pada penelitian ini didapatkan hasil yaitu terjadi peningkatan yang signifikan terhadap aktivitas fungsional lumbal pada pasien HNP dengan modalitas berupa TENS, PNF, dan McKenzie exercise, yang diukur menggunakan (ODI).

\section{DAFTAR PUSTAKA}

Alim, A. (2010). Latihan Fleksibilitas Dengan Metode PNF. Surakarta: Politeknik Kesehatan Kemenkes Surakarta.

Aulia, L. A. (2015). Penatalaksanaan Fisioterapi Pada Stroke Non Hemoragik Dengan Modalitas Terapi Latihan PNF. Surakarta: Universitas Muhammadiyah Surakarta. 
Budiono, A. (2016). Pengaruh Latihan Proprioceptive Neuromuscular Facilitation (PNF) Pasca Cedera Bahu Terhadap Perbaikan Range Of Motion (ROM). E-JOURNAL, 1-5.

Cahyati, Y. I. (2015). Penatalaksanaan Fisioterapi Pada Kondisi Hernia Nucleus Pulposus Pada L5-S1 di Rsud Salatiga. KTI, Universitas Muhammadiah Surakarta.

Fatmasari, D. (2016). Hubungan Antara Obesitas Sentral dengan Derajat Hernia Nukleus Pulposus. Makassar: Universitas Hasanuddin.

Hayes, K. H., \& Hall, K. D. (2016). Agen Modalitas untuk Praktik Fisioterapi. Jakarta: EGC.

Hendrik. (2018). Pengaruh Latihan PNF Terhadap Peningkatan Daya Tahan Otot Tungkai Pasien Post Stroke Di RSUD Salewangan Maros. Makassar: Politeknik Kesehatan Makassar.

Jhonson, M. (2009). Transcutaneous Electrical Nerve Stimulation. Continuing Education in Anaesthesia Critical Care \& Pain.

Jordan , J., Kika, K., \& John , O. (2009). Herniated Lumbar Disc. BMJ Publishing Group Ltd. HIm 2.

Jumiati, J. (2015). Penambahan Core Stabilization Exercise Lebih Menurunkan Disabilitas Di Bandingkan Dengan Penambahan Latihan Metode Mckenzie Pada Traksi Manipulasi Penderita Nyeri Pinggang Bawah Mekanik Di Kota Yogyakarta .Tesis. Denpasar: Program Pascasarjana Studi Fisiologi Olahraga Universitas Udayana.

Llake, D. A. (2014). Hubungan Propioceptive Neuromuscular Facilitation (PNF) Arm Exercise terhadap Activity Daily Living (ADL) lengan pada penderita Post Stroke di RSUD Salewangang Kab. Maros Kota Makassar. Universitas Hasanuddin Makassar.

Nugroho, F., Weta, W., Sugijanto, Griadhi, I. A., Satriyasa, B. K., \& Irfan, M. (2018). Penambahan Nerve Stretching Lebih Baik Dibandingkan Nerve Gliding Setelah Mc Kenzie Exercise Dalam Menurunkan Gangguan Sensorik Dan Meningkatkan Fleksibilitas Nervus Ischiadicus Pada Hernia Nucleus Pulposus Lumbal. Sport and Fitness Journal, 91-101.

Pranata, S., Nugroho, H., \& Sujianto, U. (2016). Pengaruh Transcutaneous Electrinal Nerve Stimulation (TENS) Terhadap Penyembuhan Luka. Jurnal Keperawatan dan Pemikiran IImiah, 1-12.

Roselina, E., Arifin, S., \& Gidion, H. (2014). Manajemen Nyeri Pasien Rawat Jalan Pada Kasus Hernia Nukleus Pulposus Melalui Core Stability. Jurnal Vokasi Indonesia, 13-21.

Saputri, O. D. (2016). Pengaruh Core Stability Exercise Dan Mckenzie Exercise. Surakarta: Universitas Muhammadiyah Surakarta.

Septiana, R. W. (2015). Perbedaan Pengaruh Penambahan Slump Stretching Pada Intervensi TENS Terhadap Penurunan Nyeri Pada Penderita Low Back Pain. Skripsi. Yogyakarta: Sekolah Tinggi Ilmu Kesehatan Aisiyah Yogyakarta.

Sudaryanto, \& Islam, F. (2018). Kombinasi Teknik Proprioceptive Neuromuscular Facilita Tion Dan Mc.Kenzie Exercise Lebih Efektif Daripada Mc.Kenzie Exercise Terhadap Perubahan Fungsional Lumbal Pada Penderita HNP Lumbal. 59-65.

Surya, A. P. (2015). Penatalaksanaan Fisioterapi Pada Kondisi Hernia Nucleus Pulposus L4-L5 di RST Prof. Dr. Soedjono Magelang. Surakarta: Universitas Muhammadiyah Surakarta.

Tanderi, E. A., K, T. A., \& Hendrianingtyas, M. (2017). Hubungan Kemampuan Fungsional Dan Derajat Nyeri Pada Pasien Low Back Pain Mekanik di Instalasi Rehabilitasi Medik Rsup Dr. Kariadi Semarang. Jurnal Kedokteran Diponegoro, 63-72. 
Volume 2 No. 1 (April, 2020)

Yuniar, J, A., \& Susy, P. (2013). Pemberian Pilates Exercise Sama Dengan McKenzie Exercise Dalam Penurunan Skor Disability Index Pada Penderita HNP di Klinik Bali Chiroparactic. Jurnal Fisioterapi, HIm 83-86. 